\author{
B.D. Koshanov ${ }^{1,2}$, A.P. Soldatov ${ }^{3}$ \\ ${ }^{1}$ Institute of Mathematics and Mathematical Modeling, Almaty, Kazakhstan; \\ ${ }^{2}$ Abai Kazakh National Pedagogical University, Almaty, Kazakhstan; \\ ${ }^{3}$ Federal Research Center «Computer Science and Control» of Russian Academy of Sciences, Moscow, Russia \\ (E-mail: koshanov@list.ru)
}

\title{
On the solvability of the boundary value problems for the elliptic equation of high order on a plane
}

\begin{abstract}
For the elliptic equation of $2 l-$ th order with of constant (and only) real coefficients we consider boundary value problem of the normal derivatives $\left(k_{j}-1\right)$ order, $j=1, \ldots, l$, where $1 \leq k_{1}<\ldots<k_{l} \leq 2 l-1$. When $k_{j}=j$ it moves into the Dirichlet problem, and when $k_{j}=j+1$ it moves into the Neumann problem. In this paper, the study is carried out in space $C^{2 l, \mu}(\bar{D})$. We found the condition for Fredholm solvability of this problem and computed the index of this problem.
\end{abstract}

Keywords: elliptic equation, boundary value problem, Dirichlet problem, Neumann problem, solvability of BVP.

\section{Introduction}

From the viewpoint of an explicit description of the conditions of solvability of Fredholm and of index for this problem has been studied [1] in the class

$$
u \in C^{2 l}(D) \cap C^{2 l-1, \mu}(\bar{D}), \quad \sum_{0 \leq r \leq 2 l} a_{r, 2 l} \frac{\partial^{2 l} u}{\partial x^{2 l-r} \partial y^{r}} \in C^{\mu}(\bar{D}) .
$$

In this paper, under the assumption that $\Gamma \in C^{2 l, \mu}$ obtained in the paper [1] results extend to a standard class $C^{2 l, \mu}(\bar{D})$, which no longer depends on the equation (1).

In [2-8], an explicit form of the Green function of the Dirichlet problem for a polyharmonic equation in a multidimensional ball is constructed. The paper $[9,10]$ is devoted to the investigation of the solvability of various boundary value problems for a polyharmonic equation in a multidimensional ball. In this paper we obtain a necessary and sufficient condition for the problem to be Fredholm in terms of the original data, that is, from the right-hand side of the inhomogeneous polyharmonic equation and from the right-hand sides of the inhomogeneous boundary conditions. The correct restrictions of the stationary Navier-Stokes equation in a three-dimensional cube are described in [11], and the correct boundary conditions for the pressure in the medium are determined. In [12], initial-boundary value problems for the equations of motion of a viscous heat-conducting gas are studied with allowance for a magnetic field with cylindrical and spherical symmetry. In this paper, we prove theorems on the existence and uniqueness of solutions as a whole with respect to the time of initialboundary value problems. In [13], a brief summary of the theory of extensions and contractions of operators in Hilbert space is given, and certain classes of well-posed boundary value problems for the bi-Laplace operator are written out. The Green function of the Neumann problem for the Poisson equation in a multidimensional ball is constructed in [14].

\section{Formulation of the problem}

In simply connected region $D$ in the plane bounded by a simple smooth contour $\Gamma$, we consider the elliptic equation

$$
\sum_{0 \leq r \leq k \leq 2 l} a_{r k}(z) \frac{\partial^{k} u}{\partial x^{k-r} \partial y^{r}}=g(z), \quad z=x+i y \in D,
$$

with real coefficients $a_{r k} \in C^{\mu}(\bar{D}), 0<\mu<1$, constant at $k=2 l$. Without loss of generality we can assume that $a_{2 l, 2 l}=1$. 
The Generalized Dirichlet - Neumann problem for this equation is determined by the boundary conditions

$$
\left.\frac{\partial^{k_{j}-1} u}{\partial n^{k_{j}-1}}\right|_{\Gamma}=f_{j}, \quad j=1, \ldots, l,
$$

where $1 \leq k_{1}<k_{2}<\ldots<k_{l} \leq 2 l, n=n_{1}+i n_{2}$ means the unit external normal and under normal derivative $k$-th order we mean the expression

$$
\left(n_{1} \frac{\partial}{\partial x}+n_{2} \frac{\partial}{\partial y}\right)^{k} u=\sum_{r=0}^{k}\left(\begin{array}{l}
k \\
r
\end{array}\right) n_{1}^{r} n_{2}^{k-r} \frac{\partial^{k} u}{\partial x^{r} \partial y^{k-r}} .
$$

Fredholm solvability of the problem

As usual Fredholm property and the index of the problem are understood in relation toward its restricted operator

$$
C^{2 l, \mu}(\bar{D}) \rightarrow C^{\mu}(\bar{D}) \times \prod_{j=1}^{l} C^{2 l-k_{j}+1, \mu}(\Gamma) .
$$

For derivatives of $v \in C^{r, \mu}(\Gamma), 1 \leq r \leq 2 l-1$, with respect to the parameter arc length we have the expression

$$
\left(\frac{d}{d s}\right)^{r} v=\frac{\partial^{r} v}{\partial e^{r}}+\ldots
$$

where $e=e_{1}+i e_{2}=-i n$ is the unit tangent vector to the contour $\Gamma$, tangential derivative of $r-$ order $\partial^{r} v / \partial e^{r}$ is understood as analogous (2) and the dots denote a linear differential operator of order $r-1$, whose coefficients are expressed through the function $e_{1}, e_{2}$ and derivatives of order $r-1$ inclusive. In virtue of the assumptions about the smoothness of the contour $\Gamma$ coefficients of the operator belong to the class $C^{2 l-r, \mu}(\Gamma)$. Therefore, similar to [1] boundary conditions (2) can be rewritten in the equivalent form

$$
\left(e_{1} \frac{\partial}{\partial x}+e_{2} \frac{\partial}{\partial y}\right)^{2 l-k_{j}}\left(n_{1} \frac{\partial}{\partial x}+n_{2} \frac{\partial}{\partial y}\right)^{k_{j}-1} u+L_{j}^{0} u=f_{j}^{0}, \quad 1 \leq j \leq l,
$$

with the right-hard side

$$
f_{j}^{0}=f_{j}^{\left(2 l-k_{j}\right)}+\int_{\Gamma} f_{j}(t) d_{1} t
$$

where the symbol $d_{1} t$ is an element of arc length, and operators

$$
L_{j}^{0} u=\sum_{0 \leq r \leq s \leq 2 l-2} a_{j, r s} \frac{\partial^{s} u}{\partial x^{s-r} \partial y^{r}}+\int_{\Gamma} \frac{\partial^{k_{j}-1} u}{\partial n^{k_{j}-1}} d_{1} t,
$$

with some coefficients $a_{j, r s}(z) \in C^{1, \mu}(\Gamma)$. It is clear that the operator $L^{0}=\left(L_{1}^{0}, \ldots, L_{l}^{0}\right)$ is compact $C^{2 l, \mu}(\bar{D}) \rightarrow C^{1, \mu}(\Gamma)$.

Consider the map

$$
\mathcal{D} u=\left(U_{1}, \ldots, U_{2 l}\right), \quad U_{j}=\frac{\partial^{2 l-1} u}{\partial x^{2 l-j} \partial y^{j-1}},
$$

that acts from $C^{2 l, \mu}(\bar{D})$ in the space $C^{1, \mu}(\bar{D})$ of vector-functions satisfying the relations

$$
\frac{\partial U_{j}}{\partial y}=\frac{\partial U_{j+1}}{\partial x}, \quad 1 \leq j \leq 2 l-1 .
$$

The core of this operators $\operatorname{ker} \mathcal{D}$ is the class $P_{2 l-2}$ of all polynomials of degree at most $2 l-2$, which is equal to the dimension of $l(2 l-1)$.

As in [1] introduce the right-hand operator $\mathcal{D}^{(-1)}$, so that any function $u \in C^{2 l, \mu}(\bar{D})$ uniquely represented in the form

$$
u=\mathcal{D}^{(-1)} U+p, \quad p \in P_{2 l-2},
$$

where the vector-function $U \in C^{1, \mu}(\bar{D})$ satisfying the relations (5). 
Substituting this representation in (1) and using (4), from the elliptic equation can come to the equivalent first order system

$$
\frac{\partial U}{\partial y}-A \frac{\partial U}{\partial x}+L^{1}\left(\mathcal{D}^{(-1)} U+p\right)=g^{1}
$$

with $2 l \times 2 l-$ matrix

$$
A=\left(\begin{array}{ccccc}
0 & 1 & 0 & \ldots & 0 \\
0 & 0 & 1 & \ldots & 0 \\
\cdot & \cdot & \cdot & \ldots & \cdot \\
0 & 0 & 0 & \ldots & 1 \\
-a_{0} & -a_{1} & -a_{2} & \ldots & -a_{2 l-1}
\end{array}\right), \quad a_{r}=a_{r, 2 l},
$$

with the right-hand side $g^{1}=(0, \ldots, 0, g)$ and the operator

$$
L^{1} v=\left(0, \ldots, 0, L_{2 l}^{1} v\right), \quad L_{2 l}^{1} v=\sum_{0 \leq r \leq k \leq 2 l-1} a_{r k} \frac{\partial^{k} v}{\partial x^{k-r} \partial y^{r}} .
$$

Note that the operator $L^{1}$ is compact $C^{2 l, \mu}(\bar{D}) \rightarrow C^{\mu}(\bar{D})$.

With respect to the matrix $C=\left(C_{j k}\right) \in C^{2 l-1, \mu}(\Gamma)$, the elements of which are defined by the relations

$$
\sum_{k=1}^{2 l} C_{j k}(t) z^{k-1}=\left[e_{1}(t)+e_{2}(t) z\right]^{2 l-k_{j}}\left[-e_{2}(t)+e_{1}(t) z\right]^{k_{j}-1}, 1 \leq j \leq l,
$$

the boundary conditions (4) can be written in the form

$$
C U^{+}+L^{0}\left(\mathcal{D}^{(-1)} U+p\right)=f^{0},
$$

where the symbol + indicates the limit value functions. Recall that appearing here the operator $L \mathcal{D}^{(-1)}$ is compact $C^{1, \mu}(\bar{D}) \rightarrow C^{1, \mu}(\Gamma)$.

We write the characteristic polynomial equation (1) in the form

$$
\sum_{r=0}^{2 l} a_{r, 2 l} z^{r}=\prod_{k=1}^{m}\left[\left(z-\nu_{k}\right)\left(z-\overline{\nu_{k}}\right)\right]^{l_{k}}, \quad \operatorname{Im} \nu_{k}>0
$$

and with each vector-function $g(z)=\left(g_{1}(z), \ldots, g_{n}(z)\right)$, analytic in the neighborhood of the point $\nu_{1}, \ldots, \nu_{m}$. We introduce block $n \times l-$ matrix

$$
W_{g}\left(\nu_{1}, \ldots, \nu_{m}\right)=\left(W_{g}\left(\nu_{1}\right), \ldots, W_{g}\left(\nu_{m}\right)\right)
$$

where the matrix $W_{g}\left(\nu_{k}\right) \in \mathbb{C}^{n \times l_{k}}$ is composed of column - vectors

$$
g\left(\nu_{k}\right), g^{\prime}\left(\nu_{k}\right), \ldots, \frac{1}{\left(l_{k}-1\right) !} g^{\left(l_{k}-1\right)}\left(\nu_{k}\right)
$$

We introduce block $2 l \times 2 l-$ matrix

$$
\begin{gathered}
\widetilde{B}=(B, \bar{B}), \quad B=W_{h}\left(\nu_{1}, \ldots, \nu_{m}\right) \in \mathbb{C}^{2 l \times l}, \\
\widetilde{J}=\operatorname{diag}(J, \bar{J}) \quad J=\operatorname{diag}\left(J_{1}, \ldots, J_{m}\right),
\end{gathered}
$$

where $h(z)=\left(1, z, \ldots, z^{2 l-1}\right)$ and

$$
J_{k}=\left(\begin{array}{ccccc}
\nu_{k} & 1 & 0 & \ldots & 0 \\
0 & \nu_{k} & 1 & \ldots & 0 \\
\cdot & \cdot & \cdot & \ldots & \cdot \\
0 & 0 & 0 & \ldots & 1 \\
0 & 0 & 0 & \ldots & \nu_{k}
\end{array}\right) \in \mathbb{C}^{l_{k} \times l_{k}}
$$

is a Jordan cell, corresponding to the eigenvalue $\nu_{k}$.

As shown in [1], the matrix $\widetilde{B}$ is reversible and transfers in $A$ to Jordan form $\widetilde{J}$, i.e. we have the equality

$$
\widetilde{B}^{-1} A \widetilde{B}=\widetilde{J}
$$


Obviously, the operation of multiplication by a matrix $\widetilde{B}^{-1}$ transforms real $2 l$ - vector-functions $U$ in the complex vector-function $\widetilde{\phi}$ block form $(\phi, \bar{\phi})$. Wherein

$$
\left(\widetilde{B}^{-1} L_{A} \widetilde{B}\right) \widetilde{\phi}=\left(L_{J} \phi, \overline{L_{J} \phi}\right),
$$

where for brevity

$$
L_{A}=\frac{\partial}{\partial y}-A \frac{\partial}{\partial x}, \quad L_{J}=\frac{\partial}{\partial y}-J \frac{\partial}{\partial x} .
$$

Recall that the operator $\mathcal{D}^{-1}$, appearing in (7), (8), is defined on $2 l$ - the vector-functions $U \in C^{1, \mu}(\bar{D})$, satisfying the conditions (5). In terms of projector $Q$, acting according to the formula

$$
(Q U)_{j}=\left\{\begin{array}{cc}
U_{j}, & 1 \leq j \leq 2 l-1 \\
0, & j=2 l
\end{array}\right.
$$

these conditions can be described in the form $Q L_{A} U=0$. As shown in [1], there is limited to $C^{1, \mu}(\bar{D})$ projector $P$ with the image $\operatorname{im} P=\left\{U \in C^{1, \mu}(\bar{D}), Q L_{A} U=0\right\}$. This operator is constructed as follows [1].

We choose $\rho$ so large that the closed region $\bar{D}$ is contained in the disc $D_{0}=\{|z|<\rho\}$. Then there is a bounded operator $C^{\mu}(\bar{D}) \rightarrow C^{\mu}\left(\bar{D}_{0}\right)$ continuation, denoted by $\varphi \rightarrow \widehat{\varphi}$, with properties

$$
\left.\widehat{\varphi}\right|_{D}=\varphi,\left.\quad \widehat{\varphi}\right|_{\partial D_{0}}=0
$$

To every non-zero complex number $z=x+i y$ we associate an invertible matrix $z_{J}=x 1+y J$, where 1 is a single $l \times l$ - matrix. We introduce the integral operator

$$
\left(I^{1} \varphi\right)(z)=\frac{1}{\pi i} \int_{D}(t-z)_{J}^{-1} \widehat{\varphi}(t) d_{2} t, \quad z \in D
$$

where $d_{2} t$ is the area element. This expression is the bounded mapping $C^{\mu}(\bar{D}) \rightarrow C^{1, \mu}(\bar{D})$ and is a right-hard inverse of $L_{J}$, i.e.

$$
L_{J} I^{1} \varphi=\varphi
$$

Taking into account

$$
\left(\widetilde{B}^{-1} I \widetilde{B}\right) \widetilde{\varphi}=\left(I^{1} \varphi, \overline{I^{1} \varphi}\right), \quad \widetilde{\varphi}=(\varphi, \bar{\varphi}),
$$

obtain an operator $I$, acting in the space $C^{\mu}(\bar{D})$ of real $2 l$ - vector-functions, which in view of (12) has a similar property in relation to $L_{A}$. In our notation the desired projector $P$ is defined by $P=1-I Q L_{A}$.

As in [1] via this projector from (7), (8) we can move on to the problem

$$
L_{A} U+L^{1}\left(\mathcal{D}^{(-1)} P U+p\right)=g^{1}, \quad C U^{+}+L^{0}\left(\mathcal{D}^{(-1)} P U+p\right)=f^{0},
$$

which is already considered in the whole space $C^{1, \mu}(\bar{D})$. Since $Q L^{0}=0$, from the first equation of this problem it follows $Q L_{A} U=Q f^{1}$. Therefore, if the right side $f^{1}$ has the property $Q f^{1}=0$, i.e. $f_{j}^{1}=0,1 \leq j \leq 2 l-1$, then any solution $U$ problems (14) satisfies the condition (5). In other words, for the given right-hand side $f^{1}$ problem (14) is equivalent to (7), (8).

We use further substitution

$$
U=\widetilde{B} \widetilde{\phi}, \quad \widetilde{\phi}=(\phi, \bar{\phi}),
$$

according to which we introduce the operators $L^{(1)}: C^{1, \mu}(\bar{D}) \times P_{2 l-2} \rightarrow C^{\mu}(\bar{D})$ and $L^{(0)}: C^{1, \mu}(\bar{D}) \times P_{2 l-2} \rightarrow$ $\rightarrow C^{\mu}(\Gamma)$, acting according to the formulas

$$
\left(L^{(1)}(\phi, p), \overline{L^{(1)}(\phi, p)}\right)=\widetilde{B}^{-1} L^{1}\left(\mathcal{D}^{(-1)} P \widetilde{B} \widetilde{\phi}+p\right), \quad L^{(0)}(\phi, p)=L^{0}\left(\mathcal{D}^{(-1)} P \widetilde{B} \widetilde{\phi}+p\right) .
$$

Then, taking into account (11), (12) the substitution of (15) leads (14) to the following equivalent problem

$$
L_{J} \phi+L^{(1)}(\phi, p)=f^{1}, \quad 2 \operatorname{Re}(C B \phi)+L^{(0)}(\phi, p)=f^{0},
$$

where we put $\widetilde{B}^{-1} g^{1}=\left(f^{1}, \overline{f^{1}}\right)$, which is considered in the class $C^{1, \mu}(\bar{D}) l$ - complex vector-functions $\phi$. 
So far all reviews have been carried out in the same way as [1] with the difference that in this work problem (16) is considered in the class of functions $\phi \in C^{\mu}(\bar{D}) \cap C^{1}(D)$, for which $L_{J} \phi \in C^{\mu}(\bar{D})$. Following [2], we introduce the generalized Cauchy type integrals

$$
\left(I^{0} \psi\right)(z)=\frac{1}{2 \pi i} \int_{\Gamma}(t-z)_{J}^{-1} d t_{J} \psi(t), \quad z \in D,
$$

with a density $\varphi \in C^{1, \mu}(\Gamma)$, where witch respect to the point $t=t_{1}+i t_{2}$ on the curve $d t_{J}$ is a complex matrix differential $d t_{1} 1+d t_{2} J$ and contour $\Gamma$ positively oriented with respect to $D$. It is important to note that it has the property

$$
L_{J} I^{0} \varphi^{0}=0 .
$$

The Cauchy type integrals answer corresponding singular integral

$$
\left(S^{0} \psi\right)\left(t_{0}\right)=\frac{1}{\pi i} \int_{\Gamma}\left(t-t_{0}\right)_{J}^{-1} d t_{J} \psi(t), \quad t_{0} \in \Gamma,
$$

which is understood in the sense of the Cauchy principal value. Note that in the case of a scalar matrix $J=i$ the operator $S^{0}$ becomes classic singular Cauchy operator, denoted by $S$. As shown in [3], operators $S$ and $S^{0}$ are bounded in the spaces $C^{\mu}(\Gamma), C^{1, \mu}(\Gamma)$, and the difference $S^{0}-S$ is a compact operator. In addition, by the differentiation formulas given in [3] the operator $L^{0}$ is bounded $C^{1, \mu}(\Gamma) \rightarrow C^{1, \mu}(\bar{D})$ and just corresponds to an analogue of Sokhotskii - Plemelj

$$
\left(I^{1} \varphi\right)^{+}=\left(\varphi+S^{1} \varphi\right) / 2 .
$$

Based on these results, similarly to the classical theory of singular operators [4] we show that under the assumption of

the operator

$$
\operatorname{det}[C(t) B] \neq 0, \quad t \in \Gamma
$$

$$
N^{0} \psi=\operatorname{Re}\left[C B\left(\psi+S^{0} \psi\right)\right]
$$

acting in the space of real $l$ - of vector-functions $\psi \in C^{1, \mu}(\Gamma)$, is Fredholm and its index is given by

$$
\text { ind } N^{0}=-\left.\frac{1}{\pi}[\arg \operatorname{det}(C B)]\right|_{\Gamma} .
$$

Further arguments are similar to those given in [1]. As this paper shows any function $\phi \in C^{1, \mu}(\bar{D})$ can by uniquely represented in the form

$$
\phi=I^{1} \varphi^{1}+I^{0} \varphi^{0}+i \xi, \quad \xi \in \mathbb{R}^{l}
$$

with some complex $l$ - vector-function $\varphi^{1} \in C^{\mu}(\bar{D})$ and real $\varphi^{0} \in C^{1, \mu}(\Gamma)$. The substitution of this representation in (16) given (13), (17), (18) reduces the problem to an equivalent system of integral equations

$$
\begin{gathered}
\varphi^{1}+L_{J}\left(I^{0} \varphi^{0}+i \xi\right)+L^{(1)}\left(I^{1} \varphi^{1}+I^{0} \varphi^{0}+i \xi, p\right)=f^{1} ; \\
\operatorname{Re}\left[C B\left(\varphi^{0}+S^{0} \varphi^{0}\right)\right]+2 \operatorname{Re}\left[C B\left(I^{1} \varphi^{1}+i \xi\right)\right]+L^{(0)}\left(I^{1} \varphi^{1}+i \xi, p\right)=f^{0} .
\end{gathered}
$$

In the notation (20) we write it briefly in the operator form

$$
N^{0} \varphi^{0}+M^{00} \varphi^{0}+M^{01} \varphi^{1}+T^{0}(p, \xi)=f^{0}, \quad \varphi^{1}+M^{10} \varphi^{0}+M^{11} \varphi^{1}+T^{1}(p, \xi)=f^{1},
$$

with the relevant operators $T^{i}$ and

$$
\begin{gathered}
M^{00} \varphi^{0}=L^{(0)} I^{0} \varphi^{0}, \quad M^{01} \varphi^{1}=2 \operatorname{Re}\left(C B I^{1} \varphi^{1}\right)+L^{(0)} I^{1} \varphi^{1} \\
M^{10} \varphi^{0}=L^{(1)} I^{0} \varphi^{0}, \quad M^{11} \varphi^{1}=L^{(1)} I^{1} \varphi^{1} .
\end{gathered}
$$

Since the operators $L^{(0)}$ and $L^{(1)}$ are compact, in the operator matrix

$$
M=\left(\begin{array}{ll}
M^{00} & M^{01} \\
M^{10} & M^{11}
\end{array}\right)
$$

acting in the space $C^{1, \mu}(\Gamma) \times C^{\mu}(\bar{D})$, all elements except $M^{01}$ are compact. Therefore, by the general theory of Fredholm operators [5] the operators $N=\operatorname{diag}\left(N^{0}, 1\right)$ and $N+M$ are Fredholm equivalent and their indices 
coincide. Recalling that $\operatorname{dim} P_{2 l-2}=l(2 l-1)$ and $\xi \in \mathbb{R}^{l}$, taking into account (20) and the corresponding properties of Fredholm operators we conclude that the next theorem is proved.

Theorem. Suppose that condition

$$
\operatorname{det}[C(t) B] \neq 0, \quad t \in \Gamma
$$

is satisfied. Then the problem (1), (2) is Fredholm in the class $C^{2 l, \mu}(\bar{D})$, and its index $æ$ is calculated by the formula

$$
æ=-\left.\frac{1}{\pi}[\arg \operatorname{det}(C B)]\right|_{\Gamma}+2 l^{2},
$$

where the increment of a continuous branch of the argument on the contour $\Gamma$ is taken in the counterclockwise direction.

\title{
Acknowledgements
}

The work was supported by Grant AP 05135319 Ministry of Education and Science of Republic Kazakhstan.

\section{References}

1 Koshanov, B.D., \& Soldatov, A.P. (2016). Differential Equations, 52, 12, 1594-1609.

2 Soldatov, A.P. (2004).Journal Mathematics sciences, 17, 1-111.

3 Abapolova, E.A., \& Soldatov, A.P. (2010). Scientific statements BSU, 76, 5, 6-20.

4 Muskhelishvili, I.N. (1968). Singular integral equations. Moscow: Nauka.

5 Palais, R.S. (1965). Seminar on the Atiyah-Singer Index theorem, Princeton: Princeton Univ. Press.

6 Kalmenov, T.Sh., Koshanov, B.D., \& Nemchenko, M.Y. (2008). Complex variables and Elliptic equations, 53, $2,177-183$.

7 Kalmenov, T.Sh., Koshanov, B.D., \& Nemchenko, M.Y. (2008). Doklady Mathematics, 78, 1, 528-530.

8 Koshanov, B.D., \& Koshanova, M.D. (2015). AIP Conference Proceedings, 1676, 20020. dx.doi. Retrieved from http://dx.doi.org/10.1063/1.4930446.

9 Kanguzhin, B.E., \& Koshanov, B.D. (2010). Ufa Mathematical Journal, 2, 41-52.

10 Koshanov, B.D. (2014). AIP Conference Proceedings, 1611, 119-127.

11 Koshanov, B.D., \& Otelbaev, M.O. (2016). AIP Conference Proceedings, 1759, 020005, dx.doi.. Retrieved from http://dx.doi.org/10.1063/1.4959619.

12 Koshanov, B.D., \& Smatova, G.D. (2016). AIP Conference Proceedings, 1759, 020050. dx.doi. Retrieved from http://dx.doi.org/10.1063/1.4959664.

13 Koshanov, B.D., \& Smatova, G.D. (2017). AIP Conference Proceedings, 1880, 020050. dx.doi. Retrieved from http://dx.doi.org/10.1063/1.5000653.

14 Sadybekov, M.A., Torebek, B.T., \& Turmetov, B.K. (2014). AIP Conference Proceedings, 1611, 255-260.

\author{
Б.Д. Қошанов, А.П. Солдатов
}

\section{Жазықтықта жоғары дәрежелі эллиптикалық теңдеулер үшін шеттік есептердің шешімділігі туралы}

\begin{abstract}
Мақалада тұрақты (тек жоғары дәрежелері) нақты коэффициентті $2 l$-дәрежелі, шекарада $\left(k_{j}-1\right)$ дәрежелі нормал туындылары берілген шеттік есептер қарастырылған, $j=1, \ldots, l, 1 \leq k_{1}<\ldots<$ $<k_{l} \leq 2 l-1$. Бұл есеп $k_{j}=j$ болған кезде - Дирихле есебі, ал $k_{j}=j+1$ кезде Нейман есебі болады. Авторлар осы есептің фредгольмді шешімділігінің шартын тауып, индексін есептеген.
\end{abstract}

Kiлm сөздер: эллиптикалық теңдеулер, шеттік есептер, Дирихле есебі, Нейман есебі, шеттік есептердің шешімділігі. 
Б.Д. Кошанов, А.П. Солдатов

\section{О разрешимости краевых задач для эллиптического уравнения высокого порядка на плоскости}

В статье для эллиптического уравнения 2 l-го порядка с постоянными (и только старшими) вещественными коэффициентами рассмотрена краевая задача, заключающаяся в задании нормальных производных $\left(k_{j}-1\right)$-го порядка, $j=1, \ldots, l$, где $1 \leq k_{1}<\ldots<k_{l} \leq 2 l-1$. При $k_{j}=j$ она переходит в задачу Дирихле, а при $k_{j}=j+1-$ в задачу Неймана. Авторами найдено условие фредгольмовой разрешимости этой задачи и вычислен индекс.

Ключевые слова: эллиптическое уравнение, краевые задачи, задача Дирихле, задача Неймана, разрешимость краевых задач. 